\title{
A GESTÃO DE CONFLITOS PARA O BRASIL A PARTIR DA PERSPECTIVA PRAGMÁTICO-SISTÊMICA E A UTILIZAÇÃO DO MODELO DO TRIBUNAL MULTIPORTAS COMO PROPOSTA
}

\section{Guilherme Christen Möller*}

Resumo: Este artigo explora o panorama sobre a forma contemporânea de como o Brasil gere os seus conflitos, e após, a proposta de uma gestão de conflitos sistêmica, na perspectiva de responder ao problema desta pesquisa: a utilização de uma gestão de conflitos a partir da proposta pragmático-sistêmica pode oferecer um repertório congruente para gerir esse colapso existente no Poder Judiciário? Por meio de um estudo pragmático-sistêmico, obtêm-se, na conclusão, a utilização de uma gestão de conflitos sistêmica possibilita adequar o conflito com a forma de tratamento de conflito mais congruente para proporcionar efetividade no resultado desse conflito.

Palavras-chave: Direito Processual Civil; Gestão de conflitos; Brasil; Matriz pragmáticasistêmica; Tribunal Multiportas de Acesso à Justiça.

\section{THE CONFLICT MANAGEMENT FOR BRAZIL FROM THE PERSPECTIVE PRAGMATIC-SYSTEM AND THE USE OF THE MULTI-DOOR COURTHOUSE SYSTEM AS PROPOSAL}

\begin{abstract}
This article explores the panorama on the contemporary form of how Brazil manages its conflicts, and after, the proposal of a systemic conflict management, in the perspective of responding to the problem of this research: the use of a conflict management from the proposal of pragmati-system matrix can provide a congruent repertoire to manage this collapse in the Judiciary? Through a pragmatic-system study, are obtained, in conclusion, the use of a systemic conflict management makes it possible to adjust the conflict in the most consistent form of conflict handling to provide effectiveness in the outcome of this conflict.
\end{abstract}

Keywords: Civil Procedure Law; Conflict management; Pragmatic-system matrix; Brazil; Multi-door Courthouse System

\footnotetext{
* Mestrando em Direito Público pelo Programa de Pós-Graduação em Direito da Universidade do Vale do Rio dos Sinos (UNISINOS). Bolsista do Programa de Excelência Acadêmica (PROEX) da Coordenação de Aperfeiçoamento de Pessoal de Nível Superior (CAPES). Bacharel em Direito pela Universidade Regional de Blumenau (FURB). Autor de livros e de artigos científicos relacionados ao Direito Processual Civil. Membro do Instituto Brasileiro de Direito Processual (IBDP) e da Associação Brasileira de Direito Processual (ABDPro). Advogado e Consultor Jurídico. Currículo Lattes: http://lattes.cnpq.br/0168074867678392. Endereço postal: Programa de Pós-Graduação em Direito da Universidade do Vale do Rio dos Sinos (UNISINOS) - São Leopoldo (RS). E-mail: contato.guilhermemoller@gmail.com.
}

Revista Brasileira de História do Direito| e-ISSN: 2526-009X| Porto Alegre | v. 4 | n. 2 | 


\section{INTRODUÇÃO}

O Brasil enfrenta uma crise em seu Poder Judiciário, notadamente na quantidade de processos em tramitação simultânea, aliás, algo que não é uma constatação recente, afinal, já em 2015 noticiava-se que o Brasil havia atingido a marca de 100.000.000 (cem milhões) de processos tramitando, número que é gradualmente ampliado com o decorrer dos anos. Diante desse cenário caótico, algo deve ser feito.

Mostra-se curioso tentar entender o porquê de termos atingido essa quantidade assustadora de processos - e processo, aqui, no sentido de opção pela utilização da via jurisdicional de tratamento de conflito.

As explicações para justificar essa quantidade de processos podem ser diversas, como, por exemplo, a inexistência de uma legislação específica - que seja em algum momento de, até mesmo, uma legislação geral -, dando voz à outras formas de tratamento de conflitos, como conciliação, mediação, arbitragem, dentre outras. Esse cenário se deu por décadas. Neste ponto surge o que se denomina por "cultura da terceirização do processo", ou seja, da atitude dos litigantes acabarem por atribuir ao Estado o tratamento de seus conflitos.

Entretanto, a realidade é inegável e precisa ser trabalhada para que os conflitos, que naturalmente existirão, do Brasil possam ser resolvidos da melhor e mais eficiente forma possível. Assim nasce a proposta para este estudo.

A partir da utilização de um método pragmático-sistêmico, busca-se responder ao seguinte problema de pesquisa: a utilização de uma gestão de conflitos a partir da proposta pragmático-sistêmica pode oferecer um repertório congruente para gerir esse colapso existente no Poder Judiciário?

Buscando responde ao questionado, num primeiro momento deste trabalho, buscarse-á compreender - isso, a partir de uma dentre tantos outros fatores - do porquê o Brasil atingiu essa vasta marca de processos judiciais tramitando de forma simultânea. Assim, temse como objetivo específico para este trabalho a investigação do panorama sobre a forma brasileira contemporânea de gestão de conflitos.

A partir dos resultados obtidos no objetivo específico deste trabalho, o segundo momento, representando a proposta de objetivo geral, encarrega-se de investigar a matriz pragmático-sistêmica e qual a sua benesse de utilização para a proposta de uma gestão de conflitos no Brasil, isso, utilizando-se como modelo de referência a teoria do Tribunal Multiportas de Acesso à Justiça.

Nessa proposta, tem-se a hipótese de que, objetivando responder o problema de pesquisa, a formação da matriz pragmático-sistêmica, contando-se com suas características especialmente após a contribuição de Niklas Luhmann -, se mostra como um uma proposta para apresentar uma gestão de conflitos congruente à perspectiva complexa que se vivencia no 
que cerne aos conflitos complexos de uma sociedade complexa, emanando de aí a proposta de formulação da gestão de conflitos sistêmica. Como meio de concretização dessa proposta, tem-se a utilização da teoria do Tribunal Multiportas de Acesso à Justiça (Multi-door Courthouse System), visto que, a partir da sua característica pluralista de formas de tratamento de conflitos, englobando-se, inclusive, a jurisdição, há um leque de possibilidades de vias de tratamento de conflitos.

\section{O PANORAMA SOBRE A FORMA BRASILEIRA CONTEMPORÂNEA DE GESTÃO DOS CONFLITOS}

Noticiava-se no ano de 2015 que o Brasil havia batido a marca 100.000.000 (cem milhões) de processos tramitando de forma simultânea no Poder Judiciário, isso, claro, numa perspectiva lato sensu, afinal, englobando-se os processos em tramitação na justiça comum e em justiças especializadas. (CONJUR, 2015). Para melhor contextualizar esse número - já desatualizado em relação aos dados deste ano de 2018 -, segundo o levantamento realizado no ano de 2017, utilizando-se como ano-base 2016, apenas a Justiça Estadual brasileira conta com a tramitação simultânea de $83.764 .834^{1}$ (oitenta e três milhões e setecentos e sessenta e quatro mil e oitocentos e trinta e quatro). (CNJ, 2017, p. 34). Diante desses dados, perguntase: como e por que se chegou a tal altíssima marca de processos judiciais tramitando no Brasil?

Curiosamente, objetivando responder ao questionado, haveria a possibilidade de formulação das mais diversas hipóteses, para os mais diversos motivos, entretanto, um assunto que possui ligação direta para com essa assustadora realidade na quantidade de processos em tramitação no Poder Judiciário é a postura adotada pelo Brasil na gestão dos conflitos de sua sociedade.

Muito se vê, e cada vez mais, principalmente no ambiente acadêmico, uma vulgata acerca do reconhecimento da garantia fundamental de acesso à justiça e da garantia ao acesso à tutela jurisdicional, por via de um processo judicial, como sinônimos. Nada mais errôneo do que este pensamento, afinal, trata-se de questões distintas.

\footnotetext{
${ }^{1}$ TJ - São Paulo: 25.943.503; TJ - Rio de Janeiro: 13.448.660; TJ - Minas Gerais: 6.048.754; TJ - Rio Grande do Sul: 4.491.617; TJ - Paraná: 4.137.586; TJ - Bahia: 4.866.587; TJ - Santa Catarina: 4.032.751; TJ - Distrito Federal e Territórios: 1.180.350; TJ - Pernambuco: 2.556.504; TJ - Goiás: 2.281.900; TJ - Ceará: 1.540.955; TJ - Espírito Santo: 1.523.585; TJ - Mato Grosso: 1.531.781; TJ - Pará: 1.478.669; TJ - Maranhão: 1.445.245; TJ - Paraíba: 815.341; TJ - Mato Grosso do Sul: 1.130.831; TJ - Rio Grande do Norte: 890.102; TJ - Sergipe: 565.799; TJ - Rondônia: 551.418; TJ - Amazonas: 1.126.590; TJ - Piauí: 635.037; TJ - Tocantins: 447.281; TJ - Alagoas: 619.644; TJ - Acre: 183.610; TJ - Amapá: 163.002; TJ - Roraima: 127.732. CNJ. Conselho Nacional de Justiça. Justiça em números 2017: ano-base 2016. Brasília: CNJ, 2017. Disponível em: <http://www.cnj.jus.br/files/conteudo/arquivo/2017/12/b60a659e5d5cb79337945c1dd137496c.pdf>. Acesso em: 1. set. 2018.
}

Revista Brasileira de História do Direito | e-ISSN: 2526-009X| Porto Alegre | v. 4 | n. 2 |

p. $37-55$ | Jul/Dez. 2018 
A Constituição Federal de 1988, em seu art. 5, inc. XXXV, garante que "a lei não excluirá de apreciação do Poder Judiciário lesão ou ameaça a direito”. (BRASIL, 1988). A tal garantia atribui-se a nomenclatura de "princípio da inafastabilidade da tutela jurisdicional". (THEODORO JÚNIOR, 2016). Observa-se, deste modo, que o problema da questão já está enraizado na cultura jurídica, a ponto de que se cria um ônus interpretativo equivocado sobre tal premissa, a ponto de que o próprio reconhecimento dessa garantia, e por consequência a sua própria nomenclatura, está trabalhando o acesso à justiça e o acesso à tutela jurisdicional como se fossem sinônimos. Sobre isso, cabe uma explicação neste momento, sendo o deslinde - a partir de uma das possíveis vertentes - para a conclusão do que se se questiona acima.

Contemporaneamente, tal garantia constitucional não corresponde - e nem poderia corresponder -, tão somente, a garantia da tutela do Estado sobre um conflito a partir da via processual judicial. O processo judicial, na proposta de ser uma forma de tratamento de conflitos, mostra-se como uma dentre uma pluralidade de formas de tratar o conflito. Entretanto, tal conclusão é observada com tal clareza apenas diante da proposta para um Estado Democrático de Direito.

Na perspectiva da historicidade, essa marca que se obteve já em 2015 nada mais é do que um mero resultado que já se esperava por décadas passadas diante do fato da existência de uma forte cultura, especialmente por parte da mentalidade da população em como tratar o conflito, de terceirização dos seus litígios. (MÖLLER, 2018a).

\footnotetext{
Pensa-se, dessa forma, que o resultado atingido no ano de 2015 nada mais é do que um reflexo de má exploração pelo Estado de outros meios para a resolução de conflitos que não fosse o julgamento por um terceiro, no caso atual, do Estado-juiz, sendo que a população tem parcela mínima de culpa nessa crise presenciada pelo Poder Judiciário, vez que as leis que estavam à eles disponíveis os remetiam a almejar o processo como exclusividade na resolução de conflitos, descartando outros meios tão efetivos quanto a jurisdição. (MÖLLER, 2018a, p. 267).
}

Veja-se que, e tomando por base o Código de Processo Civil, afinal, na perspectiva da sua característica de generalidade ${ }^{2}$, bem como diante da sua história, é o principal mecanismo desenvolvido com o propósito de apresentar maneiras para a gestão dos conflitos no Brasil. Assim, partindo-se da análise dos Códigos de Processo Civil de 1939 e do Código de Processo Civil de 1973, uma semelhança encontrada mora justamente no fator de como tratam a questão desse universo pluralista de outras tantas formas de tratamento de conflitos

\footnotetext{
2 "Contudo, não apenas as questões de direito civil são solucionadas pelo processo civil, mas também as de direito comercial e até as de direito público não penal que não caibam em outros ramos especializados do direito processual". THEODORO JÚNIOR, Humberto. Curso de Direito Processual Civil. 57. ed. rev. atual. e ampl. Rio de janeiro: Forense, 2016. v. 1: Teoria Geral do Direito Processual Civil, Processo de Conhecimento e Procedimento Comum. p. 5.
} 
que não o processo judicial - aliás, faz-se uma ressalva, mesmo que supérflua, ao último código.

Sobre a primeira legislação, analisando-se no todo, o Código de Processo Civil de 1939 não dispõe de qualquer norma que assegure o tratamento dos conflitos sociais apresentados pelos litigantes ao Poder Judiciário que não seja o processo judicial. Em momento algum, em tal legislação, vê-se a menção a formas de tratamento de conflitos como, v.g., conciliação, mediação ou, ainda, arbitragem. Já a segunda legislação, notadamente o Código de Processo Civil de 1973, até menciona a existência de outras formas de tratamento de conflitos, como por exemplo os autocompositivos, porém, trata-se de uma menção inócua, visto que não apresentava qualquer mecanismo concreto a fim de efetivar a utilização dessas outras formas de tratamento de conflitos ${ }^{3}$. (MÖLLER, 2018a).

Assim, é natural pensar que diante de dessa singularidade de formas de tratamento de conflitos apresentada aos litigantes, a mentalidade da população brasileira começa a ser esculpida no sentido de enxerga no processo o único meio possível para a resolução dos seus conflitos. É aqui que nasce, assim, a cultura da terceirização dos litígios, cultura pautada na ideia de que delegar ao Poder Judiciário a atribuição da resolução dos conflitos entre as pessoas é algo natural. "Parecem assumir sua incapacidade de superar suas desavenças, transferindo essa função ao Estado". (FERNANDES, 2016, p. 10). Na realidade, pensando-se em uma perspectiva cultural, esse pensamento sobre a terceirização do litígio não se dá por exclusividade deles, mas sim pelo pensamento litigante do contexto social em que foram criados. Portanto, parece-nos que esse colapso que o Poder Judiciário vem vivenciando cada vez mais no tocante a um afogamento de varas judiciais com processos é resultado direto novamente, sendo esta uma das tantas outras perspectivas que poderiam ser levadas em conta para explicar o problema - dessa má gestão dos conflitos administrada por décadas. (MÖLLER, 2018b).

Outrossim, essas constatações históricas permitem observa justamente aquilo que se destacou alhures neste capítulo, in casus, que, de fato, há um enraizamento na cultura jurídica de forma e considerar a garantia ao acesso à justiça e a garantia à tutela jurisdicional, por via de um processo judicial, como sinônimos. Aqui, então, postular pela garantia do indivíduo de ter acesso à justiça seria o mesmo que postular pela garantia do indivíduo de ter acesso ao processo.

Em contraponto, e na perspectiva de Fernandes (2016), a garantia constitucional de acesso à justiça deve ser tratada como sinônimo de garantia de acesso às diversas formas existentes sobre tratamento de conflitos. É inviável pensar que, com as influências

\footnotetext{
${ }^{3}$ Nesse sentido, por exemplo, vê-se que no inc. IV, art. 125, do CPC/1973, prevê que competia ao juiz "tentar, a qualquer tempo, conciliar as partes". Curiosamente, tal disposição foi tão incompreendida que levava diversos juízes - não todos - a designarem audiências de conciliação com apenas 5 (cinco) minutos. BRASIL. Lei no 5.869, de 11 de janeiro de 1973. Código de Processo Civil. Brasília, DF, jan. 1973. Disponível em: <http://www.planalto.gov.br/ccivil_03/leis/L5869.htm〉. Acesso em: 1. set. 2018.
} 
contemporâneas sobre o instituto do acesso à justiça, o inc. XXXV, do art. $5^{\circ}$, da Constituição Federal de 1988, apenas zela pelo acesso à justiça pela via da própria jurisdição.

Certo é, de qualquer forma, que quando a Constituição Federal consagra o princípio da inafastabilidade da tutela jurisdicional (art. $5^{\circ}$, inciso XXXV, da Constituição Federal), tal previsão constitucional deve ser interpretada como garantia das partes à ordem jurídica justa, aos meios adequados de solução de controvérsias, não obrigatoriamente pela via da heterocomposição, e muito menos necessariamente pela via jurisdicional estatal. (FERNANDES, 2016, p. 11).

A garantia constitucional de acesso à justiça, nessa visão contemporânea, vai muito além da garantia pela via da jurisdição, zelando-se, portanto, v.g., pelo tratamento do conflito pela via da arbitragem, pelo tratamento do conflito pela via da autocomposição, dentre tantas outras, entretanto, e ponto relevante a ser destacado, ressalvando-se em últimas circunstâncias, ou seja, na não ocorrência, v.g., do tratamento de um conflito pela via da mediação ou da conciliação, a utilização do tratamento do conflito pela via jurisdicional, além de ser uma das possibilidades, mostra-se como salvaguarda constitucional, a qual sempre será um direito indisponível de qualquer litigante. (SOUZA; FERNANDES, 2016).

Entretanto, um problema mora justamente no fato do tratamento do conflito pela via da jurisdição ser uma salvaguarda constitucional de acesso à justiça. A questão de a via jurisdicional dever ser vista como o último refúgio do direito de acesso à justiça dos cidadãos não significa dizer que ela deve sofrer prévio condicionamento à outras formas de tratamento de conflitos. A tal atividade atribui-se o nome de "jurisdição condicionada", ou, "instância administrativa de curso forçado”, o que explica Moraes (2003, p. 80):

Inexiste a obrigatoriedade de esgotamento da instância administrativa para que a parte possa acessar o Judiciário. A Constituição Federal de 1988, diferentemente da anterior, afastou a necessidade da chamada jurisdição condicionada ou instância administrativa de curso forçado, pois já se decidiu pela inexigibilidade de exaurimento das vias administrativas para obter-se o provimento judicial, uma vez que excluiu a permissão, que a Emenda Constitucional n. ${ }^{\circ} 7$ à Constituição anterior estabelecera, de que a lei condicionasse o ingresso em juízo à exaustão das vias administrativas, verdadeiro obstáculo ao princípio do livre acesso ao Poder Judiciário.

Sobre esse assunto, opondo-se aos outros dois Código de Processo Civil que o antecederam, o Código de Processo Civil de 2015 possui, dentre suas tantas outras características peculiares, conta com um ar versátil acerca do reconhecimento e da apresentação de mecanismos a fim de viabilizar a utilização de outras formas para tratar o conflito que não o processo. Nesse sentido, v.g., mostra-se a norma fundamental do processo 
compreendida precisamente no art. $3^{\circ}$ do $\mathrm{CPC} / 2015^{4}$, em que tal codificação promove um considerável esforço na promoção de formas autocompositivas de tratamento de conflitos, bem como, o expresso reconhecimento da arbitragem. (MÖLLER, 2018a).

Na realidade, diferente do que se mostra, a descentralização do processo judicial como monopólio para o exercício da garantia constitucional de acesso à justiça começa a aparecer já no ano de 1995, com a Lei n. 9.099/95 (dispondo acerca dos Juizados Especiais), especialmente com a sua proposta de um procedimento judicial não tão burocrático quanto os - àquela época - procedimento sumário e, especialmente, o procedimento ordinário, posteriormente no ano de 1996, com a Lei n. 9.307/96 (dispondo sobre a arbitragem) mesmo que já devidamente reconhecida na própria lei dos juizados especiais -, e, a posteriori, 14 (quatorze) anos após essa última lei, no caso, no ano de 2010, com a Resolução n. 125/2010 5 do Conselho Nacional de Justiça, sendo considerado o principal conjunto normativo destinado a dispor sobre a ideia de meio consensual para o tratamento de conflitos. (DIDIER JÚNIOR, 2015).

Nessa proposta incentivada principalmente pelo Código de Processo Civil de 2015 de apostar principalmente em forma de tratamento de conflitos pela via autocompositiva, frente ao atual momento em que o Brasil registra essa demasiada carga de processos judiciais em trâmite, desvirtua-se a finalidade dessa proposta e a cogita como sendo a possibilidade de serem a panaceia para o colapso do Poder Judiciário brasileiro. (MÖLLER, 2018a). Portanto, surgem outras duas vulgatas, a um, que essas formas autocompositivas de tratamento de conflitos podem ser o remédio para solucionar a crise numérica de processos judiciais do Brasil e, justamente por isso, a dois, devem ser priorizados em detrimento da jurisdição.

Uma advertência mostra-se necessária. Todas as formas de tratamento de conflitos não constituem apenas uma reminiscência histórica, com ressalvas à autotutela - quando não for legalmente prevista no ordenamento jurídico. Pensando-se numa perspectiva da vivência em uma sociedade complexa, e, por consequência, com conflitos complexos, todas essas formas de tratamento de conflitos possuem o seu respectivo espaço e papel. (FERNANDES, 2016).

\footnotetext{
4 “Art. $3^{\circ}$ Não se excluirá da apreciação jurisdicional ameaça ou lesão a direito. $\S 1^{\circ}$ É permitida a arbitragem, na forma da lei. $\S 2^{\circ} \mathrm{O}$ Estado promoverá, sempre que possível, a solução consensual dos conflitos. § $3^{\circ} \mathrm{A}$ conciliação, a mediação e outros métodos de solução consensual de conflitos deverão ser estimulados por juízes, advogados, defensores públicos e membros do Ministério Público, inclusive no curso do processo judicial”. BRASIL. Lei n ${ }^{\circ} 13.105$, de 16 de março de 2015. Código de Processo Civil. Brasília, DF, mar. 2015. Disponível em: <http://www.planalto.gov.br/ccivil_03/_ato2015-2018/2015/lei/113105.htm>. Acesso em: 2. set. 2018.

5 "Esta Resolução, por exemplo: a) institui a Política Pública de tratamento adequado dos conflitos de interesses $\left(\right.$ art. $\left.1^{\circ}\right)$; b) define o papel do Conselho Nacional de Justiça como organizador desta política pública no âmbito do Poder Judiciário (art. $4^{\circ}$ ); c) impõe a criação, pelos tribunais, dos centros de solução de conflitos e cidadania (art. $\left.7^{\circ}\right)$; d) regulamenta a atuação do mediador e do conciliar (art. 12), inclusive criando o seu Código de Ética (anexo da Resolução); e) imputa aos centros de solução de conflitos e cidadania (art. 13); f) define o currículo mínimo para o curso de capacitação dos mediadores e conciliadores". DIDIER JÚNIOR, Fredie. Curso de Direito Processual Civil. 17. Ed. Salvador: Juspodivm, 2015, v.1, p. 274.
} 
Pensar a jurisdição como sendo uma forma natural, e, por conta disso, ser a principal, de tratamento dos conflitos, tratando as demais formas como alternativas, e, por conta disso, serem secundárias em relação à jurisdição, em outras palavras, idealizar utopicamente uma hierarquia de formas de tratamento de conflitos, vai em sentido divergente ao esperado numa perspectiva contemporânea para a garantia constitucional de acesso à justiça, afinal, e como destacou-se alhures, busca-se, hoje, ir além da garantia do acesso à justiça pela via da jurisdição, garantindo-a, sem qualquer distinção, por via de todas as outras formas de tratamento de conflitos existentes e que porventura surgiram de acordo com o movimento autopoiético da sociedade. Ressalva-se, no entanto, que a jurisdição estatal sempre será a salvaguarda constitucional de acesso à justiça a qualquer litigante. (MÖLLER, 2018b).

Assim, mostra-se como errôneo pensar que essas formas de tratamento de conflitos pela via autocompositivas, ou ainda, pela via da arbitragem, seriam a solução/panaceia para a crise vivenciada pelo Poder Judiciário brasileiro no tocante ao alto número de processos judicias em tramitação. Trata-se de um pensamento doentio, sendo a sua prática considerada como "perigosa e ilícita", especialmente "a postura de alguns juízes que constrangem as partes à realização de acordos judiciais”. (DIDIER JÚNIOR, 2015, p. 279/280).

\begin{abstract}
A conciliação não pode e não deve ser prioritariamente vista como forma de desafogar o Poder Judiciário. Ela é desejável essencialmente porque é mais construtiva. O desafogo vem como consequência, e não como a meta principal. Essa constatação é importante: um enfoque distorcido do problema pode levar a resultados indesejados. Vista como instrumento de administração de máquina judiciária, a conciliação passa a ser uma preocupação com estatísticas. Sua recusa pelas partes - direito mais do que legítimo - passa a ser vista como uma espécie de descumprimento de um dever cívico e, no processo, pode fazer com que se tome como inimigo do Estado aquele que não está disposto a abrir mão de parte do que entende ser seu direito. Daí a reputar a parte intransigente como litigante de má-fé vai um passo curto. Isso é a negação de garantia constitucional da ação e configura quebra do compromisso assumido pelo Estado de prestar justiça. Esse mesmo Estado proíbe que o cidadão, salvo raras exceções, faça justiça pelas próprias mãos. (YARSHELL, 2009, p. A3).
\end{abstract}

O problema central na gestão de conflitos brasileira contemporânea, na realidade, surge a partir do momento em que se afirme que uma forma de tratamento de determinado conflito seja mais adequada que outro. Exemplificando-se, seria o mesmo que dizer, v.g., que a mediação e/ou a conciliação são mais adequadas para tratar os conflitos da sociedade do que a forma de tratamento apresentada pela via da jurisdição. No caso dessa parcela doutrinária, selecionam-se determinadas formas de tratamentos de conflito e denominam-nas como "meios adequados de solução de conflitos", ou seja, desprezam-se totalmente a influência e a finalidade das demais, inclusive, nessa perspectiva, questiona-se: todas as formas de 
tratamento de conflitos que não sejam enquadras como "meios adequados de solução de conflitos" seriam inadequadas e, por consequência, ineficientes?

\begin{abstract}
Registro que não concordo com a parcela doutrinária que prefere renomear essas formas de solução dos conflitos de "meios adequados" de solução de conflitos, porque adequado é resolver o conflito, não se podendo afirmar a priori ser um meio mais adequado do que outro. Se esses são os meios adequados, o que seria a jurisdição? O meio inadequado de solucionar conflitos? Compreendo que atualmente não seja mais apropriado falar em meios alternativos, o que daria uma ideia de subsidiariedade a tais meios de solução de conflitos, mas certamente chamálos de "meios adequados" está bem longe de um nome adequado. Por isso sempre preferi chama-los simplesmente de equivalentes jurisdicionais. (NEVES, 2016, p. 8).
\end{abstract}

A atividade de buscar-se eleger uma espécie de hierarquia com todas as formas de tratamentos de conflitos e posiciona-las de acordo com a sua "eficiência" é inapropriada, isso porque o principal problema para essa atitude consiste justamente na sua generalização para uma sociedade complexa (RODRIGUES; NEVES, 2012), ainda mais no atual momento de globalização (TEUBNER, 2016), em que cada vez mais há uma pluralidade de contextos sociais, policontexturalidade (TEUBNER, 2005). (ROCHA; SCHWARTZ; CLAM, 2005). Uma forma de tratamento de conflito será adequada quando adequada for ao caso concreto, ou seja, de acordo com suas peculiaridades, observando-se as influências de subsistemas sociais sobre determinado conflito. Conflitos não são padronizados. (MÖLLER, 2018c).

Todas essas questões que foram apontadas neste capítulo devem ser levadas em conta para a formulação de uma teoria sobre a gestão de conflitos que atendam a essas peculiaridades, afinal, o que se espera é eleger um modelo para a gestão de conflito que seja eficaz a ponto de, a partir das peculiaridades existentes em cada conflito, proporcionar o resultado mais adequado para cada conflito, assegurando-se, assim, a efetividade da garantia constitucional de acesso à justiça. Sobre isso, discorrer-se-á no capítulo seguinte.

\title{
2. A GESTÃO DE CONFLITOS PELA MATRIZ PRAGMÁTICO-SISTÊMICA: A UTILIZAÇÃO DA TEORIA DO TRIBUNAL MULTIPORTAS DE ACESSO À JUSTIÇA COMO O MODELO MAIS PERTINENTE PARA ESSA PROPOSTA
}

A teoria jurídica do século XX é caracterizada pela busca em elaborar uma racionalidade própria para o Direito. (ROCHA, 2003). Assim, partindo-se desde a "Teoria Pura do Direito", de Hans Kelsen (1976), a "O conceito de Direito", de Hart (2009), o "Direito Responsivo", de Nonet e Selznick (2010), a "Teoria da Argumentação Jurídica", de Alexy (1989), entre tantas outras tentativas, até, inclusive, a "La Sociedad de la Sociedad", de 
Niklas Luhmann (2007), procurou-se construir uma perspectiva de observação para o Direito a partir de distintos pressupostos epistemológicos. (ROCHA, 2009).

O raciocínio jurídico da atualidade conta com características cartesianas, partindo-se do ponto em que a racionalidade é obtida pela utilização de um método dedutivo baseado nas evidências, demonstrações, e das relações de causalidade dos argumentos. Outrossim, o Direito seria, nesta linha, uma "metafisica com aspectos claramente ontológicos cuja essência estaria à disposição da pré-compreensão dos juristas". Tal raciocínio, entretanto, é ultrapassado com as perspectivas da Matriz Sistêmica, a qual buscava tal sentido na estrutura e abandonam as visões metafísicas da verdade atomizada. (ROCHA, 2009, p. 142).

A proposta dessa Matriz Sistêmica é fomentada por consideráveis contribuições de Niklas Luhmann - especialmente os seus últimos trabalhos, notadamente, a partir da Sociologia das Organizações, e de conceitos como os de risco e paradoxo, permitem um passo à frente para a compreensão da hipercomplexidade da sociedade atual. Conciliando-se as propostas de Luhmann para com essa matriz, tem-se a constituição de uma Matriz Pragmático-Sistêmica, responsável por provocar uma mudança epistemológica na teoria jurídica, possibilita-se uma observação de segunda ordem do contato na teoria jurídica entre os aspectos externos e internos, entre a práxis e a teoria, superando as concepções dogmáticas dominantes. (ROCHA, 2003).

\footnotetext{
Esta matriz realmente provoca uma mudança epistemológica na teoria jurídica. O ponto de partida são as análises de Luhmann sobre a Teoria dos Sistemas Sociais. Niklas Luhmann adaptaria alguns aspectos da teoria de Parsons (2010). Porém, na maturidade, Luhmann voltou-se para uma perspectiva autopoiética (Maturana e Varela, 1996), acentuando a sistematicidade do Direito como organização da sociedade. A perspectiva sistêmica autopoiética (pragmático-sistêmica) permite afirmar que, por trás de todas as dimensões da semiótica, notadamente, as funções pragmáticas da linguagem nos processos de decisão jurídica, estão presentes, redefinidas no interior do sistema, a problemática do risco e do paradoxo. Nesta linha de ideias, pode-se entender porque Luhmann define o Direito como "uma estrutura de generalização congruente". (ROCHA, 2009, p. 147).
}

No caso, para a Sociologia do Direito, na proposta de Luhmann, "o comportamento social em um mundo altamente complexo e contingente exige a realização de graduações que possibilitem expectativas comportamentais recíprocas e que são orientadas a partir de expectativas sobre tais expectativas". (ROCHA, 2009, p. 147). A forma como pode-se dar tais reduções ocorrem através de três dimensões: temporal, social e prática. Outrossim, num mundo altamente complexo e contingente, o comportamento social requer reduções necessárias que possibilitarão expectativas comportamentais recíprocas e que são orientadas partindo das expectativas sobre tais expectativas. Portanto, na proposta de Luhmann (1985, p. 185) do Direito como "a estrutura de um sistema social", sua função reside na sua eficiência 
seletiva, baseada "na generalização congruente de expectativas comportamentais normativas". (ROCHA, 2009).

Embora visto como uma estrutura, o Direito, na perspectiva luhmanniana, mostra-se como dinâmico devido à permanente evolução decorrente da sua necessidade de constantemente agir como uma das estruturas sociais de redução da complexidade das possibilidades do ser no mundo. (ROCHA, 2009).

A breve digressão acerca da matriz pragmático-sistêmica, evidenciando-se as suas principais características, apresenta a possibilidade de sua - eficiente - compatibilização para com a gestão dos conflitos brasileiros, especialmente diante das peculiaridades destacadas ao final do último capítulo. Se se parte da ideia de que se vive numa sociedade complexa, ou, como prefere Rocha (2009), uma sociedade hipercomplexa, deve-se ter em mente que os conflitos oriundos dessa sociedade serão, de mesma forma, complexos. Os conflitos são complexos posto que a configuração da sociedade se apresenta como complexa.

Uma proposta para a gestão de conflitos contemporânea atenta ao fato de buscar, cada vez mais, proporcionar um resultado mais efetivo, principalmente para o resultado alcançado ao fim do tratamento do conflito, deve, e sempre, levar em conta a inexistência de uma padronização dos conflitos da sociedade. (MÖLLER, 2018c). Outrossim, é a partir da "prática" que se pode vislumbrar as singularidades das configurações de cada conflito. Cada conflito é oriundo de um determinado contexto, o que faz nascer a necessidade da observação de conflitos policontexturais. (TEUBNER, 2005). Um determinado conflito nunca corresponderá de forma idêntica a outro, afinal, por mais que se possa vislumbrar características similares, cada qual, inevitavelmente, contará com os seus próprios elementos que farão a sua distinção em relação aos demais conflitos.

Inexoravelmente, as peculiaridades existentes em cada conflito poderão surgir a partir de diversos fatores, como, por vezes, decorrente de uma diversidade de formas de comunidades com configurações totalmente diversas a de um Estado-nação. Não se pode deixar à limiar que na seara atual da globalização uma "comunidade" não é representada única e exclusivamente pela figura de um Estado-nação, afinal, essas comunidades podem, sem qualquer espécie de "enfraquecimento" da figura do Estado-nação, serem representadas como sendo transnacionais, supranacionais, epistêmicas, ou ainda subnacionais, ou seja, a comunidade pode possuir, simultaneamente à sua plena existência, a sua comunidade da comunidade. (BERMAN, 2007). Nessa perspectiva, por exemplo, tem-se o caso brasileiro da comunidade subnacional de Pasárgada (Rio de Janeiro - RJ), grupo social estudado por Santos (1988) em sua tese doutoral.

Santos, então, passa a mostrar como uma comunidade, à margem do Estado-nação e em constante conflito com o direito oficial, como é o caso de Pasárgada, desenvolve mecanismos próprio dessa organização coletiva e, especialmente, para o tratamento dos conflitos que surgem a partir da configuração dessa determinada comunidade, como, v.g., 
conflitos envolvendo posse de terra e construções de moradias. Esse "direito não oficial", nomenclatura que é adotada para referir-se ao direito de Pasárgada, fundado na proposta de ser "um procedimento aberto permeado por uma tonalidade ético-social", constituindo-se de "um discurso jurídico mais acessível e participativo, no qual prevalece o modelo da mediação", regido por características como equilíbrio, cooperação e do "bom vizinho", acaba por possuir um amplo reconhecimento naquela comunidade não apenas pelo fato de ser mais retóricos e próximos da linguagem comum, ou seja, possuindo um grau inferior nas características formal, técnica e burocrática do que o direito oficial, ou seja, do direito estatal, mas, e principalmente, pelo fato de que se leva em consideração, quando do desenvolvimento de mecanismos para gerar os conflitos dessa comunidade, a realidade daquele contexto, ou seja, uma observação prática sobre as particularidades ali existentes. (CARVALHO, 2013, p. 17; SANTOS, 1988). Pasárgada, outrossim, mostra-se como um exemplo do que se deve ter por "desgeneralização" dos conflitos.

Mostra-se como utópico pensar que os conflitos a partir do contexto de Pasárgada serão iguais aos dos outros contextos do Brasil, e isso, claro, não apenas por conta de uma forte existência de pluralidade de organizações de comunidades, mas porque, e o que pode ser presenciado dentre dessas comunidades das comunidades, é que cada relação conflituosa terá a sua própria configuração, seja pelos agentes, seja pelo contexto, seja pelo fato, e assim sucessivamente. A pergunta que fica dessa constatação é a seguinte: como reduzir a complexidade da influência de todos esses elementos sobre os conflitos a fim de viabilizar uma melhor efetividade para o seu tratamento?

Indiscutivelmente, a partir da constatação do alto número de processos em trâmite, hoje, o Brasil registra uma forte tendência de monopolizar o exercício da "justiça" a partir de proporcionar o tratamento dos conflitos pela via da jurisdição. (MÖLLER, 2018c). Isso ocorre, entretanto - e como já visto alhures neste texto -, por diversos fatores, especialmente por uma herança cultural em enxergar o processo (processo enquanto único fim de instrumento de concretização do exercício da jurisdição) como a única forma de tratar conflitos. Outrossim, é justamente neste ponto que mora o embate para com toda a construção aqui proposta: ora, como é possível aferir que a jurisdição será a forma mais congruente de tratamento desses conflitos policontexturais?

A fim de responder aos dois questionamentos que foram destacados acima, e na proposta de Luhmann (2016), a redução da complexidade presente nos conflitos complexos contemporâneos dessa sociedade complexa, apenas será possível a partir da adoção de uma teoria que seja igualmente complexa. Assim, a complexidade, quando confrontada por outra complexidade, acaba por ser reduzida.

Nessa proposta, uma teoria que se mostra como suficiente para atender à essa constatação, especialmente pelo deslocamento do campo de observação da gestão de conflitos para a prática, e consequentemente obter maior efetividade no resultado desses conflitos, é o Tribunal Multiportas de Acesso à Justiça (Multi-door Courthouse System). 
Desenvolvido pelo falecido professor alemão da Escola de Negociação da Universidade de Harvard, Frank Sander propõe a utilização de uma "instituição [...] que direciona os processos que chegam a um tribunal para os mais adequados métodos de resolução de conflitos, economizando tempo e dinheiro tanto para os tribunais quanto para os participantes ou litigantes". (ALMEIDA; ALMEIDA; CRESPO, 2012). Outrossim, trata-se de um modelo que propõe uma pluralidade de formas para tratamento dos conflitos a partir do seu correto molde ao conflito policontextural. Conflito complexo somado com a utilização de um modelo complexo como o Tribunal Multiportas de Acesso à Justiça, resulta na redução da complexidade da gestão de conflitos.

\footnotetext{
Agora, gostaria de dar uma breve explicação sobre o conceito, seja qual for o nome dado. A ideia inicial é examinar as diferentes formas de resolução de conflitos: mediação, arbitragem, negociação e "med-arb" (combinação de mediação e arbitragem). Procurei observar cada um dos diferentes processos, para ver se poderíamos encontrar algum tipo de taxonomia para aplicar aos conflitos, e que portas seriam adequadas a quais conflitos. Venho trabalhando nessa questão desde 1976, porque na verdade o Tribunal Multiportas é uma simples ideia, cuja execução não é simples, porque decidir que casos devem ir para qual porta não é uma tarefa simples. É nisso que temos trabalhado. (ALMEIDA; ALMEIDA; CRESPO, 2012, p. 32)
}

O que se destaca dessa proposta da utilização do modelo do Tribunal Multiportas de Acesso à Justiça como modelo de concretização de uma gestão de conflitos sistêmica é o fato de que se rompe com a ideia de utilização exclusiva da jurisdição como forma para tratar conflitos e que se obtenha um resultado efetivo aos interessados em resolver esse conflito a partir de uma pluralidade de possibilidades de dirimir o confronto, como conciliação, mediação e arbitragem, ou ainda a própria jurisdição, afinal, ela assume o papel de salvaguarda da garantia fundamenta de acesso à justiça, propiciando a utilização dessas formas conforme a peculiaridade de cada conflito.

\section{CONCLUSÃO}

Espera-se, com esta digressão, ter respondido ao proposto como problema de pesquisa, a partir da estruturação que foi desenvolvida.

Com relação ao primeiro ponto, notadamente o primeiro objetivo específico, viu-se desde o começo que o Brasil vem enfrentando um colapso no que se refere a quantidade de processos que estão tramitando simultaneamente no Poder Judiciário. 
Noticiava-se no ano de 2015 que o Brasil havia batido a marca 100.000.000 (cem milhões) de processos tramitando de forma simultânea, número que vem aumentando de forma gradual, aliás, segundo o levantamento realizado no ano de 2017, utilizando-se como ano-base 2016, apenas a Justiça Estadual brasileira conta com a tramitação simultânea de 83.764.834 (oitenta e três milhões e setecentos e sessenta e quatro mil e oitocentos e trinta e quatro).

Ocorre que, a garantia constitucional de acesso à justiça, representada no art. $5^{\circ}$, inc. XXXV, da Constituição Federal, a que se atribui o nome de inafastabilidade da tutela jurisdicional, numa perspectiva contemporânea, não pode dar margem para trabalhar o acesso à justiça e o acesso à tutela jurisdicional como se fossem sinônimos.

A garantia constitucional de acesso à justiça, nessa visão contemporânea, vai muito além da garantia pela via da jurisdição, zelando-se, portanto, v.g., pelo tratamento do conflito pela via da arbitragem, pelo tratamento do conflito pela via da autocomposição, dentre tantas outras, entretanto, e ponto relevante a ser destacado, ressalvando-se em últimas circunstâncias, ou seja, na não ocorrência, v.g., do tratamento de um conflito pela via da mediação ou da conciliação, a utilização do tratamento do conflito pela via jurisdicional, além de ser uma das possibilidades, mostra-se como salvaguarda constitucional, a qual sempre será um direito indisponível de qualquer litigante.

Nesse momento, a partir dessa proposta, avançando-se para o objetivo geral deste trabalho e de responder ao problema de pesquisa, tem-se a Matriz Pragmático-Sistêmica, responsável por provocar uma mudança epistemológica na teoria jurídica, possibilita-se uma observação de segunda ordem do contato na teoria jurídica entre os aspectos externos e internos, entre a práxis e a teoria, superando as concepções dogmáticas dominantes, objetivado a realização de gradações que possibilitem expectativas comportamentais que visem confrontar a complexidade atual do mundo.

Sua utilização, evidenciando-se as suas principais características, apresenta a possibilidade de sua - eficiente - compatibilização para com a gestão dos conflitos brasileiros, afinal, se se parte da ideia de que se vive numa sociedade complexa, deve-se ter em mente que os conflitos oriundos dessa sociedade serão, de mesma forma, complexos.

Uma proposta para a gestão de conflitos contemporânea atenta ao fato de buscar, cada vez mais, proporcionar um resultado mais efetivo, principalmente para o resultado alcançado ao fim do tratamento do conflito, deve, e sempre, levar em conta a inexistência de uma padronização dos conflitos da sociedade. Outrossim, é a partir da "prática" que se pode vislumbrar as singularidades das configurações de cada conflito. Cada conflito é oriundo de um determinado contexto, o que faz nascer a necessidade da observação de conflitos policontexturais. Um determinado conflito nunca corresponderá de forma idêntica a outro, afinal, por mais que se possa vislumbrar características similares, cada qual, inevitavelmente, 
contará com os seus próprios elementos que farão a sua distinção em relação aos demais conflitos.

Uma teoria que se mostra como suficiente para atender à essa constatação, especialmente pelo deslocamento do campo de observação da gestão de conflitos para a prática, e consequentemente obter maior efetividade no resultado desses conflitos, é o Tribunal Multiportas de Acesso à Justiça (Multi-door Courthouse System).

Desenvolvido pelo falecido professor alemão da Escola de Negociação da Universidade de Harvard, Frank Sander propõe a utilização de uma instituição responsável por direcionar todos os processos que cheguem a um tribunal para os mais adequados métodos de tratamento de conflitos, de modo que será economizado tempo e dinheiro, tanto para os tribunais, quanto para os participantes ou litigantes. Isso significa que se trata de um modelo que propõe uma pluralidade de formas para tratamento dos conflitos a partir do seu correto molde ao conflito policontextural.

O que se destaca dessa proposta da utilização do modelo do Tribunal Multiportas de Acesso à Justiça como modelo de concretização de uma gestão de conflitos sistêmica é o fato de que se rompe com a ideia de utilização exclusiva da jurisdição como forma para tratar conflitos e que se obtenha um resultado efetivo aos interessados em resolver esse conflito a partir de uma pluralidade de possibilidades de dirimir o confronto, como conciliação, mediação e arbitragem, ou ainda a própria jurisdição, afinal, ela assume o papel de salvaguarda da garantia fundamenta de acesso à justiça, propiciando a utilização dessas formas conforme a peculiaridade de cada conflito.

\section{REFERÊNCIAS}

ALMEIDA, Rafael Alves de; ALMEIDA, Tania; CRESPO, Mariana Hernandez (Org.). Tribunal Multiportas: investindo no capital social para maximizar o sistema de solução de conflitos no Brasil. Rio de Janeiro: FGV Editora, 2012.

BERMAN, Paul Schiff. Global Legal Pluralism. Southern California Law Review, v. 80, p. $1155-1237,2007$.

BRASIL. Constituição (1988). Constituição da República Federativa do Brasil. Brasília, DF: Senado Federal: Centro Gráfico, 1988. Disponível em: 
<http://www.planalto.gov.br/ccivil_03/constituicao/constituicaocompilado.htm>. Acesso em: 30 ago. 2018.

Lei no 5.869, de 11 de janeiro de 1973. Código de Processo Civil. Brasília, DF, jan. 1973. Disponível em: <http://www.planalto.gov.br/ccivil_03/leis/L5869.htm>. Acesso em: 1. set. 2018 .

Lei no 13.105, de 16 de março de 2015. Código de Processo Civil. Brasília, DF, mar. 2015. Disponível em: <http://www.planalto.gov.br/ccivil_03/_ato20152018/2015/lei/113105.htm>. Acesso em: 2. set. 2018.

CARVALHO, Lucas Borges de. Caminhos (e descaminhos) do pluralismo jurídico no Brasil. In: WOLKMER, Antonio Carlos; VERAS NETO, Francisco Q.; LIXA, Ivone M. (Org.). Pluralismo Jurídico. São Paulo: Saraiva, 2013. p. 13 - 36.

CNJ. Conselho Nacional de Justiça. Justiça em números 2017: ano-base 2016. Brasília: CNJ, 2017. Disponível em:

<http://www.cnj.jus.br/files/conteudo/arquivo/2017/12/b60a659e5d5cb79337945c1dd137496 c.pdf $>$. Acesso em: 1. set. 2018.

CONJUR. Consultor Jurídico. Brasil atinge a marca de 100 milhões de processos em tramitação na Justiça. 2015. Disponível em: <http://www.conjur.com.br/2015-set-15/brasilatinge-marca-100-milhoes-processos-tramitacao>. Acesso em: 1. set. 2018.

DIDIER JÚNIOR, Fredie. Curso de Direito Processual Civil. 17. ed. rev. ampl. e atual. conforme o Novo CPC, o Provimento n 37/2014 (Conselho Nacional de Justiça), a Resolução $n^{\circ}$ 118/2014 (Conselho Nacional do Ministério Público) e as Leis no 13.015/2015 (Recursos de Revista Repetitivos), 13.043/2014, 13.058/2014 e 13.089/2015 (Estatuto da Metrópole). Salvador: Jus Podivm, 2015. 
FERNANDES, Luís Eduardo Simardi. Formas de solução dos litígios. In: SOUZA, André Pagani de; CARACIOLA, Andrea Boari; ASSIS, Carlos Augusto de; ; DELLORE, Luiz. Teoria Geral do Processo contemporâneo. São Paulo: Atlas, 2016. p. 7 - 19.

LUHMANN, Niklas. Sociologia do Direito. Rio de Janeiro: Tempo Brasileiro, 1985. O direito da sociedade. São Paulo: Martins Fontes, 2016.

MÖLLER, Guilherme Christen. Métodos adequados de solução de conflitos: panaceia para a crise do Poder Judiciário?. Simpósio brasileiro de Processo Civil, 2017, Curitiba. Anais do Simpósio brasileiro de Processo Civil. Curitiba: ABDConst, 2018a. p. 254 - 279. Disponível em: <http://abdconst.com.br/anais-civil/Guilherme\%20Christen\%20Moller.pdf>. Acesso em: 2. set. 2018. $2018 b$.

Pontos controversos sobre o Código de Processo Civil de 2015. Curitiba: Prismas, . O art. 695 do Código de Processo Civil de 2015 e sua proposta subjetiva de "condicionamento" da jurisdição à conciliação/mediação. Encontro Nacional do CONPEDI, XXVII, 2018, Salvador. Anais do XXVII Encontro Nacional do CONPEDI. Salvador: CONPEDI, 2018c. p. 44 - 61. Disponível em: <https://www.conpedi.org.br/publicacoes/0ds65m46/v5n81bbi/7x80Qz2ZfXMB08bX.pdf >. Acesso em: 2. set. 2018.

MORAES, Alexandre de. Direito Constitucional. 13. ed. atual. com a EC nº 39/02. São Paulo: Atlas, 2003.

NEVES, Daniel Amorim Assumpção. Novo Código de Processo Civil comentado: artigo por artigo. Salvador: Jus Podivm, 2016. 
ROCHA, Leonel Severo. Epistemologia jurídica e democracia. 2. ed. São Leopoldo: Editora Unisinos, 2003.

ROCHA, Leonel Severo; SCHWARTZ, Germano; CLAM, Jean. Introdução à teoria do sistema autopoiético do Direito. Porto Alegre: Livraria do Advogado, 2005.

ROCHA, Leonel Severo. Epistemologia do Direito: revisitando as três matrizes jurídicas. Revista de Estudos Constitucionais, Hermenêuticos e Teoria do Direito (RECHTD), v. 5, n. 2. P. 141 - 149. Disponível em:

<http://revistas.unisinos.br/index.php/RECHTD/article/view/rechtd.2013.52.06/3934>. Acesso em: 3. set. 2018.

RODRIGUES, Leo Peixoto; NEVES, Fabrício Monteiro. Niklas Luhmann: a sociedade como sistema. Porto Alegre: Edipucrs, 2012.

SANTOS, Boaventura de Sousa. Notas sobre a história jurídico-social de Pasárgada. In: SOUSA JÚNIOR, José Geraldo (Org.). O direito achado na rua. Brasília: Universidade de Brasília, 1988. p. 46-51.

SOUZA, André Pagani de/ FERNANDES, Luís Eduardo Simardi. Institutos fundamentais do Direito Processual Civil. In: ; CARACIOLA, Andrea Boari; ASSIS, Carlos Augusto de; __ _ DELLORE, Luiz. Teoria Geral do Processo contemporâneo. São Paulo: Atlas, 2016. p. $115-117$.

TEUBNER, Gunther. Direito, Sistema e Policontexturalidade. Piracicaba: Editora Unimep, 2005 .

Fragmentos Constitucionais: constitucionalismo social na globalização. São Paulo: Saraiva, 2016. 
THEODORO JÚNIOR, Humberto. Curso de Direito Processual Civil. 57. ed. rev. atual. e ampl. Rio de janeiro: Forense, 2016. v. 1: Teoria Geral do Direito Processual Civil, Processo de Conhecimento e Procedimento Comum.

YARSHELL, Flávio Luiz. Para pensar a Semana Nacional da Conciliação. 08.12.2009. São Paulo: Folha de São Paulo, 2009. 